\title{
Treatment of COPD exacerbations: antibiotics
}

\author{
R. Wilson
}

\begin{abstract}
The debate about the importance of bacterial infection in chronic obstructive pulmonary disease will continue. About half of exacerbations yield positive sputum bacteriology, and the isolation rate can be increased by selection of purulent samples.

However, bacteria are also isolated in the stable state. The presence of bacteria in sputum alone during an exacerbation does not prove causation. Bacteria have been associated with airway inflammation both in the stable state, when the level of inflammation is related to the size of the bacterial load, and during exacerbations, when resolution of the inflammation is related to bacterial eradication.

New evidence has been obtained from epidemiological, immunological and antibiotic studies that supports a role for bacterial infection in causing neutrophilic airway inflammation in chronic obstructive pulmonary disease, and if accepted should lead to new research in the use of antibiotics.
\end{abstract}

\section{KEYWORDS: Antibiotics, chronic obstructive pulmonary disease, exacerbation}

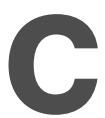
hronic obstructive pulmonary disease (COPD) encompasses several conditions (airflow obstruction, chronic bronchitis, bronchiolitis or small airways disease and emphysema) that often coexist. Patients with chronic bronchitis are more susceptible to bacterial bronchial infections than those at the emphysema or asthma end of the spectrum [1]. Mucus hypersecretion, which is the hallmark of chronic bronchitis, is particularly associated with mortality from an infectious cause [2]. These observations may be explained by the affinity with which bacteria adhere to mucus, and the delay in mucociliary clearance that occurs in chronic bronchitis, partly due to loss of ciliated cells that are replaced by goblet cells. Thus, bacteria that are inhaled or aspirated into the bronchial tree may utilise stationary mucus as the first step towards infection of the mucosa [3].

The classical studies of FLETCHER et al. [4] concluded from a prospective study of working males that chronic cough and sputum production, and recurrent respiratory infections did not relate to decline in lung function. They suggested that chronic bronchitis and airflow obstruction were both caused by cigarette smoking, but the former that was associated with bronchial infections involved major conducting airways, whereas the latter related to small airways. However, recent data has led to a re-examination of the role of bacterial infection in COPD, and a revisiting of the "British hypothesis" [5]. The new evidence can be considered under six headings: 1) lung function decline; 2) bronchoscopic studies; 3) epidemiology using new molecular biology techniques to identify bacteria; 4) immunology; 5) studies of airway inflammation; and 6) recent antibiotic studies. The conclusions of this research, if accepted, must lead to new guidelines on the use of antibiotics in COPD, because present guidelines pay scan attention to the importance of antibiotic treatment in the overall management of COPD [1].

\section{CLINICAL STUDIES INVESTIGATING BACTERIAL INFECTION AND LUNG FUNCTION DECLINE}

MURPHY and SETHI [6] reviewed older papers and found that only one of the four prospective studies showed that more frequent episodes of infection caused a more rapid decline in lung function. More recently, the Copenhagen City Study reported that patients with chronic mucus hypersecretion had more rapid rates of forced expiratory volume in one second (FEV1) decline than COPD patients without these symptoms [7]. This may be relevant because of the association between mucus hypersecretion and bacterial infection. Lower respiratory tract infections caused more FEV1 decline in current smokers with mild COPD but not ex-smokers in the Lung Health Study [8]. The frequency of exacerbations, whatever their cause, has been associated with more rapid loss of lung function, worse quality of
CORRESPONDENCE

R. Wilson

Royal Brompton Hospital

Sydney Street

London SW3 6NP

UK

Fax: 441713518338

E-mail:

r.wilson@rbh.nthames.nhs.uk 
life and quicker deterioration in quality of life $[9,10]$. A single infective exacerbation has a sustained affect on health status, and recovery is markedly impaired by a second exacerbation within a 6-month follow-up period [11]. Airway bacterial load has been related to decline in FEV1, although this study was only conducted over $1 \mathrm{yr}$ with assessment of bacteriology at the beginning and end [12]. Finally, bacterial colonisation of the bronchial tree in between exacerbations has been shown to be associated with both an increase in the severity and frequency of future exacerbations [13].

The evidence as it stands at the moment is suggestive that bacterial infections may have a role in progression of COPD, but it is far from conclusive. Future studies will need to be conducted over much longer time periods, at least 3 yrs and preferably longer, and strenuous efforts will need to be made to capture all exacerbations as well as identify their cause. It will become clear later in this article, that as well as identifying a potential bacterial pathogen from lower respiratory tract secretions, the strain should be fully identified and the numbers of bacteria calculated by quantitative sputum cultures. Lower airway bacterial colonisation (LABC) during a stable phase of COPD probably represents a balance in which the impaired host defences are able to limit the numbers of bacteria, but not eradicate them. LABC is a dynamic process, so that strains may be carried for variable periods of time before being lost and replaced by others. What is not clear at the moment is the extent to which LABC influences airway inflammation and the frequency of exacerbations [1]. Therefore, the design of future long-term studies should involve seeing patients regularly, whatever their clinical status, as well as asking them to present to the centre during all exacerbations $[9,14,15]$. The design of such studies will be a major challenge requiring an enormous effort from both the investigators and their patients.

\section{BRONCHOSCOPIC STUDIES}

Most of the bacterial species isolated from sputum during exacerbations of COPD colonise the nasopharynx of healthy individuals, and can be isolated from the lower airways of COPD patients during stable phases of their disease [1, 14]. There is general agreement that the most commonly isolated species are nontypable Haemophilus influenzae, Streptococcus pneumoniae and Moraxella catarrhalis. About half of exacerbations yield positive sputum bacteriology, and the isolation rate may be increased by selection of purulent samples [16, 17]. Bronchoscopy permits the investigator to sample the lower airways directly, avoiding contamination of sputum in the nasopharynx during expectoration, and in some studies biopsies have been taken of the mucosa. Disadvantages of bronchoscopy include the difficulties associated with performing repeat studies, and sampling error, e.g. the protected specimen brush biopsy takes a sample from only a small part of one airway.

Four bronchoscopy studies have given similar results: $\sim 25 \%$ of COPD patients have LABC when in a stable phase. The proportion of patients with positive bacteriology, defined by quantitative counts and identification of species that are recognised as pathogens, increases to $\sim 50 \%$ during an exacerbation. The species identified are predominantly one of the three given above and the bacterial numbers are much greater during an exacerbation [18-21]. Current cigarette smoking predisposes to $\mathrm{LABC}$, but studies have disagreed whether airflow obstruction is a predisposing factor. As yet no longitudinal study has been performed to examine the same patients whilst stable and exacerbated.

All studies have in addition to potential pathogens identified bacterial species in the lower airways, which in health are sterile, that are not usually regarded as lower respiratory tract pathogens, e.g. S. viridans. Perception of what is a pathogenic species can change with time, for example $M$. catarrhalis was not regarded as a pathogen for many years, and there is a debate at the present time about $H$. parainfluenzae [1]. There is little information about the propensity of different species to stimulate inflammation, and even different strains of the same species may vary in their ability to elicit an inflammatory response [22]. Consequently, the total bacterial load in the bronchial tree could be an important parameter as well as the number of the predominant pathogenic species isolated [1].

SOLER et al. [23] showed that there were higher neutrophil counts, and elevated interleukin- 8 and tumour necrosis factor$\alpha$ levels in bronchoalveolar lavage performed on stable chronic bronchitic patients with LABC by potential pathogenic bacteria compared with those without. This was the first study to suggest that LABC in the stable condition might be a stimulus for chronic inflammation, and the result has been confirmed recently in a similar designed study using sputum [24]. In another study BANDI et al. [25] examined biopsies taken from 15 critically ill patients with an acute exacerbation and found $H$. influenzae within the mucosa of 13 . The bacterium was also found in the tissue taken from eight of 24 stable COPD patients but none of seven healthy controls. Thirteen of 15 biopsy samples in a study of patients with severe exacerbations were positive for $H$. influenzae detected by monoclonal antibody [26] Neutrophil elastase-positive cells were seen in the epithelium and sub-epithelial tissues, co-locating bacteria with inflammatory cells, but this study falls short of proving that the bacteria were the cause of the inflammation.

\section{BACTERIAL EPIDEMIOLOGY FROM SPUTUM}

There is general agreement that the three species listed above are most commonly isolated from sputum during acute exacerbations, but several studies have shown that they can also be isolated from patients sputum during stable periods [27-30]. GuMP et al. [27] carefully followed up 25 patients in clinic every 2 weeks for 4 yrs, leading to 1,870 stable sputum samples, 116 taken during exacerbations. Isolation rates of $H$. influenzae and S. pneumoniae were identical during the stable phase and during an exacerbation. A different result was obtained by FISHER et al. [31] who found an increase in the frequency with which bacteria were isolated from the same patients during exacerbations compared to stable periods. Another study found greater bacterial numbers during an exacerbation compared with the stable phase; a sputum Gram stain showed fewer than two organisms per oil immersion field when patients were stable compared with 8-18 per field at the time of an exacerbation [32].

The most compelling evidence showing that bacterial infections are an important cause of exacerbations has been 
provided by the study of SETHI et al. [15]. The design of their study was very similar to that of GUMP et al. [27] with regular follow-up visits over several years when patients are in a stable phase and additional visits at the onset of any exacerbation. However, these investigators were able to use new molecular biology techniques to accurately identify strains by DNA fingerprinting. They showed that exacerbations were twice as likely to occur when patients acquired a new strain of either $H$. influenzae, the pneumococcus, or $M$. catarrhalis compared with visits when no new strain was isolated. Thirty-three per cent of clinic visits associated with acquisition of a new bacterial strain were accompanied by an exacerbation, as compared with $15.4 \%$ of visits without acquisition of a new bacterial strain. The mechanism by which acquisition of a new strain leads to an exacerbation was not determined, but it is more likely that a new strain would not be recognised by the immune system, compared to a colonising strain that may have been present for several weeks, and this would allow it to multiply and so stimulate inflammatory responses that themselves lead to the symptoms of the exacerbation. It is also plausible that the new strain would be more successful invading the mucosa, as seen in the study of BANDI et al. [25], and that such invasion would cause epithelial damage and stimulate higher levels of inflammation.

\section{IMMUNOLOGY}

Older serological studies performed to study the role of bacteria in exacerbations have had several limitations, and have often yielded negative results. They have not taken into account the antigenic complexity of bacterial antigens of which those expressed on the surface are most relevant to the hostbacterial interactions, nor of the human immune response to those antigens. Therefore, several studies have used a mixture of specific and cross-reactive antibodies, often with laboratory bacterial strains rather than strains obtained from the patient themselves [6, 33]. SETHI et al. [34] have taken a different approach and shown that following an exacerbation during which $H$. influenzae has been isolated, there is a strain-specific immune response. This finding adds weight to the argument that the bacteria are playing a key active role in the exacerbation as they are generating a host response intended to eliminate them.

SETHI et al. [34] used the same cohort of patients as their previous study [15], and collected sputum and serum samples at each visit. This allowed them to study changes in the patient's sera before and after exacerbations, and measure the immune reaction to the patient's own exacerbating strain, then compare these results to responses obtained with strains isolated when the patient was stable. The antibodies measured were detected by both an ELISA assay and a bactericidal assay of antibody-mediated complement-dependent killing of $H$. influenzae. SETHI et al. [34] therefore measured antibodies directed against surface-exposed epitopes present on the actual strain in the airway during the exacerbation. When patients acquired a new strain at the time of an exacerbation, a specific antibody response to this strain was present $58.3 \%$ of the time, whilst only $15.2 \%$ of exacerbations with a persistent colonising strain had an antibody response. The same findings were seen with the bactericidal assay, and only $12 \%$ of heterologous strains of $H$. influenzae were killed.
The current author suspects that further work in this area will show that the host-bacterial relationships are even more complex than those described above. At the American Thoracic Society meeting in Orlando in May 2004 SETHI and colleagues [35, 36] showed new data indicating that the immune system does respond to some colonising strains, although the response is not as intense as when a new strain is acquired. Therefore, it would be wrong to assume that a colonising strain is benign and not making a contribution to chronic airway inflammation in the stable state. Acquisition of a new strain may not be a prerequisite for an exacerbation, since the numbers of a colonising strain might increase, and invasion of the mucosa might occur, if the host defences were reduced for example following a viral infection.

\section{STUDIES OF AIRWAY INFLAMMATION}

Most of the debate about the role of bacterial infection in COPD has centred upon exacerbations. Both local and systemic inflammatory responses have been repeatedly demonstrated in COPD patients during exacerbations $[1,5,6]$. The evidence reviewed above, taken together with the wealth of evidence that bacterial products generate inflammation [1], makes a strong case for bacterial infection being the cause, or at least making a significant contribution, to about half of exacerbations. Several recent studies have raised the possibility that $\mathrm{LABC}$, in the stable state might also make an important contribution to progression of COPD [5]. WHITE et al. [37] showed that resolution of bronchial inflammation following an exacerbation is dependent upon bacterial eradication. Those patients in whom bacteria continue to be cultured in the sputum only have partial resolution leading to chronic inflammation, which may be stimulated by the continued presence of bacteria in the airway.

LABC has also been linked to FEV1 decline, as well as the frequency and severity of subsequent exacerbations [12, 13]. When stable patients with COPD are investigated there is a direct relationship between the level of the sputum bacterial load and sputum inflammatory markers [38]. There seemed in this study to be a level of $10^{6}$ colony forming units per $\mathrm{mL}$ at which the inflammatory markers began to rise. Therefore, there may be a level of bacterial load that is tolerated but this is likely to be dependent on the species and strains being carried. Since LABC is a dynamic process, in that multiple bacterial strains may be carried at any one time, and they are sometimes changeable on a week-by-week basis, it might be a very unstable relationship [1]. The recent studies of SETHI and colleagues [15, 34-36] suggest that when there is chronic colonisation by a single strain the immune response begins to wane with time. Therefore, the host bacterial interaction is complex, and simply determining the presence or absence of a particular species by sputum bacteriology is inadequate for understanding the role of bacteria in COPD.

BANERJEE et al. [24] compared stable COPD patients with and without LABC by potential pathogenic species. Although there was considerable overlap between the two populations they found that patients carrying pathogenic species had more airway inflammation. Two other findings of this study are important. They found that plasma fibrinogen levels were higher in patients with sputum pathogens, and also that quality-of-life scores were worse in this group. These results 
suggest that LABC elicits a systemic response outside the lung that introduces a new dimension to the host-bacterial interaction to be considered in future studies.

\section{ANOTHER POINT OF VIEW AND OLDER ANTIBIOTIC TRIALS}

One of the interests of the current author's group is the interaction of bacteria with the respiratory mucosa in organ cultures. They have reported the cytoprotective effects in these systems of the long-acting $\beta_{2}$ agonist salmeterol [39]. Table 1 shows that this compound, which has no antibacterial action, reduced the number of Pseudomonas aeruginosa on the organ culture by reducing the amount of mucosal damage that occurred during infection. Mucosal damage releases nutrients for bacterial growth, and another plausible explanation of most of the results given in this article is that bacteria are passengers taking advantage of the mucosal environment created by inflammation that has nothing to do with bacterial infection.

The answer to this "chicken and egg" argument would seem straightforward, because treating bacterial infection is something that is readily available with antibiotics. The reason that the debate continues is that antibiotic trials have not provided the expected conclusive answer. The possible reasons for this are set out in table 2. A major problem is that most antibiotic trials are not powered adequately to demonstrate superiority, particularly as they compare one antibiotic with another rather than placebo, supposedly for ethical reasons, and since nearly half of patients recover spontaneously, and a proportion of those that fail do so for reasons other than bacterial infection [1].

A meta-analysis of placebo-controlled trials concluded that, overall, there was a small but significant benefit from antibiotic treatment of acute exacerbations of COPD in terms of overall

\begin{tabular}{|c|c|c|}
\hline \multirow[t]{2}{*}{ TABLE 1} & $\begin{array}{l}\text { duced epit } \\
\text { numbers }\end{array}$ & nage via salmeterol \\
\hline & $\begin{array}{l}\text { Damaged } \\
\text { mucosa \% }\end{array}$ & $\begin{array}{l}\text { Pseudomonas } \\
\text { aeruginosa }\end{array}$ \\
\hline Tissue alone & 68.2 & 1700 \\
\hline Tissue plus salmeterol & 52.8 & 936 \\
\hline
\end{tabular}

\section{TABLE 2 Shortcomings of older antibiotic trials in acute exacerbations of chronic obstructive pulmonary disease}

Underpowered to show differences between antibiotics

Heterogenous patient populations e.g. severity of exacerbation, comorbidity, evidence of infection

No knowledge of pre-exacerbation condition by which to evaluate recovery Lack of long-term follow up

No evaluation of co-medication likely to affect clinical outcome e.g. corticosteroids (oral, inhaled), long-acting $\beta$-agonists and anti-cholinergics

Typically studies are designed as part of registration trials to show "noninferiority" (equivalence) i.e. new agent versus carefully chosen comparator recovery and change in peak flow [40]. There have also been nine prospective placebo-controlled, randomised trials to investigate whether continuous antibiotic treatment reduces the frequency of exacerbations. These were reviewed by MuRPHY and SETHI [6]. There have been conflicting results. Five trials showed no reduction in the frequency of exacerbations whereas four did show this benefit. Two of the five trials that showed no benefit did show significantly less time lost from work in the antibiotic group, even though the frequency of exacerbations was not different from the placebo group. Patients most likely to benefit from continuous antibiotic treatment were found to be those suffering frequent exacerbations, which was judged to mean of at least four per year.

The landmark antibiotic study was performed by ANTHONISEN et al. [41]. In this study 173 patients with COPD were followed for 3.5 yrs during which time they had 362 exacerbations. Antibiotics or placebo were given in a randomised, doubleblind, crossover fashion. Three levels of severity of exacerbation were recognised: the most severe (type 1) comprised of worsening dyspnoea with increased sputum volume and purulence, type 2 was any two of these symptoms and the least severe grade (type 3) was any one of three symptoms with evidence of fever or an upper respiratory tract infection. Three antibiotics were used: amoxycillin, trimethoprim-sulphamethoxazole and doxycycline; the choice of antibiotic being made by the physician.

There was a significant benefit from antibiotics that was largely accounted for by patients with type 1 exacerbations, whereas there was no significant difference between antibiotic and placebo in patients who only had one of the defined symptoms. However, even with type 1 exacerbations, $43 \%$ of patients recovered in the placebo group within 21 days, which emphasises the difficulty in differentiating between the benefits of different antibiotics when recovery is the primary end-point of the trial. In patients with frequent exacerbations the duration of antibiotic-treated exacerbations averaged 2.2 days less than those treated with placebo $(\mathrm{p}=0.02)$. However, when all patients were considered and treatment failures were eliminated from the analysis, the benefit from antibiotics on speed of recovery was only 0.9 days, a nonsignificant difference. Peak flow returned to baseline in both groups during the study period, but the rate of increase was faster in the antibiotic-treated exacerbations.

The study of ALLEGRA et al. [42] provided further evidence of the benefit of antibiotics. Amoxycillin-clavulanate was compared with placebo and showed a clear overall superiority for the antibiotic treatment. The analysis also showed that patients with more severe impairment of FEV1 and with a history of more frequent exacerbations derived greatest benefit.

\section{RECENT ANTIBIOTIC STUDIES}

The current author been the lead investigator in three studies conducted during the last 5 yrs or so, looking at the benefit of antibiotic treatment for COPD exacerbations. Following discussions with colleagues the design of the studies has evolved to take into account issues raised in this article. A major debate has been whether considering the evidence currently available, a placebo-controlled trial is ethical in all but the mildest cases. The general view has been that it is not, although the current 
author would still argue the case for a placebo-controlled trial carried out under controlled conditions.

In the first study conducted by the current author, Treatment of Acute exaCerbaTions of chronIC bronchitis (TACTIC) [43], the quinolone antibiotic moxifloxacin $400 \mathrm{mg}$ o.d. for 5 days was compared with the macrolide antibiotic clarithromycin $500 \mathrm{mg} \mathrm{b.d}$, for 7 days. Patients with chronic bronchitis and symptoms of an Anthonisen Type 1 or 2 exacerbation were enrolled. The design of the study was standard, with the primary end-point at day 14 being physician judgement that the patient had improved sufficiently not to require further antibiotic treatment. Moxifloxacin achieved superior $(\mathrm{p}<0.05)$ bacteriological eradication (77\%) compared with clarithromycin $(62 \%)$ due to persistence of $H$. influenzae in clarithromycin treated patients. However, the clinical outcome was equivalence, in that $89 \%$ of moxifloxacin-treated patients and $88 \%$ of clarithromycin-treated patients achieved a successful outcome. The probable reason for this result is shown in table 3, which shows bacteriology results from paired sputum samples. The most common outcome was bacteriological eradication and clinical success, but in a large group (of clarithromycin treated patients) $H$. influenzae persisted but the patients still achieved success as defined by the study protocol.

In the Gemifloxacin Long-term Outcomes in Bronchitis Exacerbations (GLOBE) study [44], which followed TACTIC, the current author and colleagues asked the question whether $H$. influenzae persistence would influence the time interval until the next exacerbation. Another new quinolone antibiotic, gemifloxacin, was compared with clarithromycin using a very similar study design, but in this study only Anthonisen type 1 exacerbations were enrolled and patients followed up for 26 weeks or until they had their next exacerbation. The bacteriological and short-term outcomes of the GLOBE study were the same as the TACTIC study, but the percentage of patients who did not have a further exacerbation during the 26-week period was significantly $(p<0.05)$ greater after treatment with the quinolone antibiotic. The hypothesis put forward was that incomplete bacterial eradication by the macrolide antibiotic lead to a shorter interval until the next exacerbation, although this remains a hypothesis to be tested and is not proven.

The MOSAIC study (a multicentre, multinational, prospective, randomised, double-blind study to compare the effectiveness of Moxifloxacin Oral tablets to Standard oral antibiotic regimen given as first-line therapy in out-patients with Acute Infective

\begin{tabular}{|c|c|c|c|}
\hline \multirow[t]{3}{*}{ TABLE 3} & \multicolumn{3}{|c|}{$\begin{array}{l}\text { Bacteriological and clinical outcomes obtained } \\
\text { during a trial of moxifloxacin versus clarithromycin } \\
\text { in acute exacerbations of chronic bronchitis }\end{array}$} \\
\hline & & \multicolumn{2}{|c|}{ Bacteriological success } \\
\hline & & No & Yes \\
\hline \multirow[t]{2}{*}{ Clinical success } & No & 20 & 5 \\
\hline & Yes & 40 & 63 \\
\hline
\end{tabular}

Yes: Chi-squared $p<0.01$. Data from [43] exacerbations of Chronic bronchitis) attempted to bring all these concepts together, and by strict entry criteria achieve a pure smoking-related COPD study population [45]. First, patients were assessed during a stable phase of their illness in order to be able to make a judgement after a subsequent exacerbation as to whether the patient had made a full recovery (cure, back to baseline), or a partial recovery (sufficient not to require further antibiotic treatment). When patients had an Anthonisen Type 1 exacerbation they came back to the centre bringing with them a purulent sputum sample and were randomised to receive either moxifloxacin $400 \mathrm{mg} \mathrm{o.d}$. for 5 days or one of a basket of three comparator antibiotic chosen because they were the most common antibiotics (and dosages) used in the countries enrolling patients into the trial (amoxycillin $500 \mathrm{mg}$ t.d.s. 7 days, clarithromycin $500 \mathrm{mg}$ b.d. 7 days, cefuroxime $250 \mathrm{mg}$ b.d. 7 days). The patients were assessed shortly after the end of treatment as before. The current author also analysed results dependent upon both inhaled and oral steroid use. Patients were followed up monthly for 9 months after their exacerbation, and whether patients had risk-factors for poor outcome was taken into consideration.

The key results were that moxifloxacin achieved significantly $(p<0.05)$ superior bacteriological eradication, which was again largely due to $H$. influenzae persistence in the comparator group. The cure (return to baseline) rate with moxifloxacin was significantly $(p<0.05)$ greater, but not the success (well enough not to require a further antibiotic) rate, which was the primary end-point and showed equivalence between the antibiotics. This is an important result, in that it shows that stricter criteria are needed to judge success if differences are to be shown between antibiotics. Steroid prescription was a marker of sicker patients who overall did less well. Moxifloxacin gave superior outcomes in those patients not given steroids, but there was only a trend favouring moxifloxacin in patients given steroids. Steroids may have improved outcomes in the comparator group, making it more difficult to demonstrate differences between antibiotics. About twice as many further courses of antibiotics were prescribed to comparator treated patients $(14.1 \%$ versus $7.6 \%)$ in the few weeks following the presenting exacerbation, confirming incomplete resolution of symptoms, which led to further antibiotic prescriptions for these patients. The time until next exacerbation was longer (14 days) after moxifloxacin treatment $(\mathrm{p}<0.05)$, and this difference in exacerbation-free interval was larger in patients with risk-factors for poor outcome [46].

The important lessons from the MOSAIC study for future trial design are: enrol patients when they are stable to obtain a baseline assessment by which to judge recovery; ensure an appropriate homogenous population (e.g. mean age in MOSAIC was $>60$ yrs, there was a $>30$ pack-yr smoking history, three quarters of patients had at least one co-morbid illness, patients had had chronic bronchitis for $\geqslant 10 \mathrm{yrs}$ ); steroids mask potential differences between antibiotics; longterm follow up is required. The hypothesis of the current author, to explain the results of MOSAIC, is that bacteriological eradication permitted the mucosal inflammation to fully resolve, and local host defences to repair themselves, leading to a longer exacerbation-free interval. This hypothesis needs to be tested by further studies. 


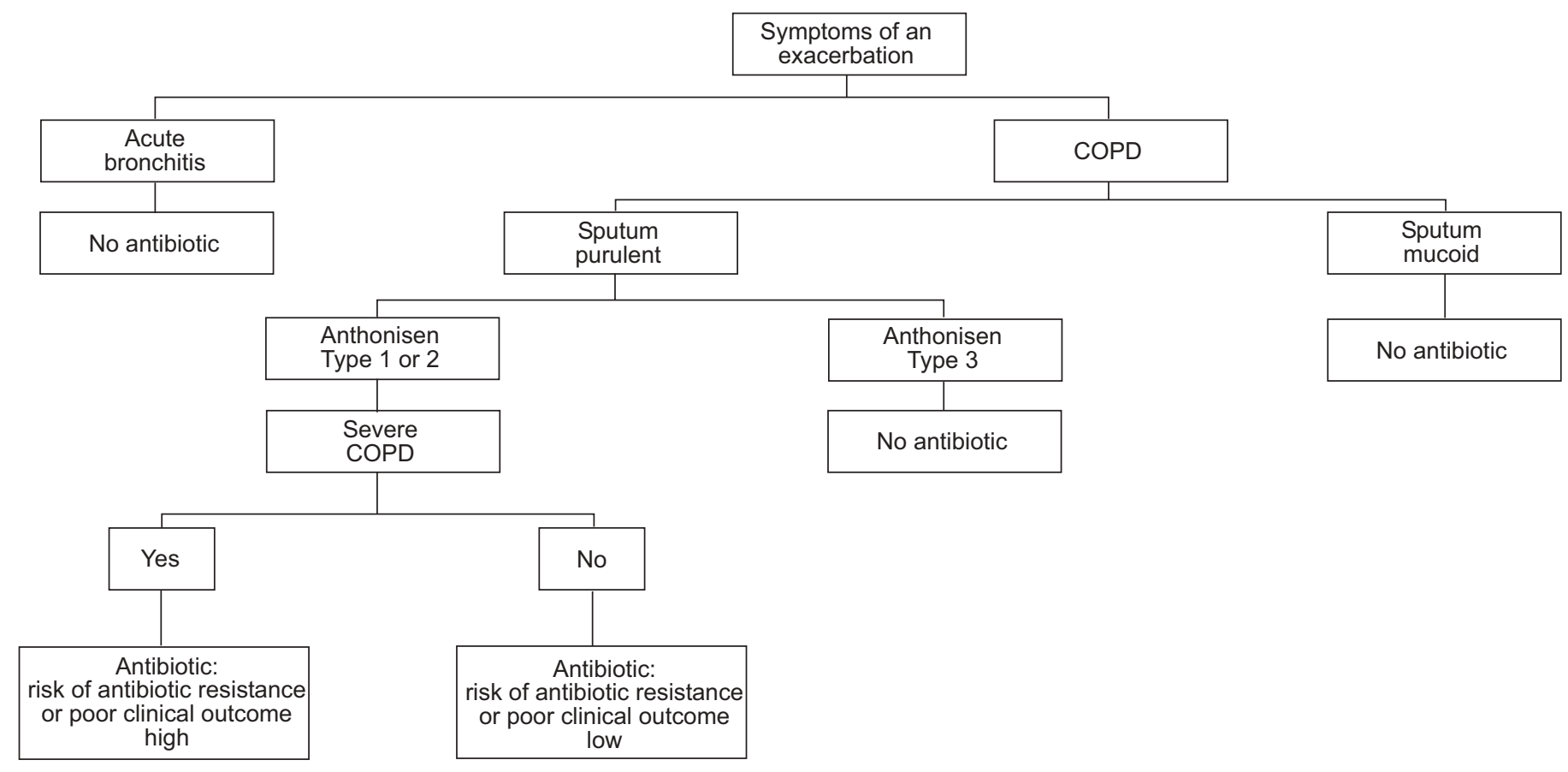

FIGURE 1. An algorithm showing which patients with an acute exacerbation of chronic obstructive pulmonary disease (COPD) should receive antibiotic treatment.

\section{TREATMENT GUIDELINES}

The guidelines of learned societies have differed in what they advise about antibiotics and chronic obstructive pulmonary disease [1]. The majority have not had the opportunity to consider the data covered in this article. Most have leaned heavily on the study by ANTHONISEN et al. [41]. An algorithm used by the current author that incorporates the Anthonisen criteria and also emphasises the importance of purulent sputum is shown in figure 1. This illustrates which patients should be treated with an antibiotic. The evidence is less strong to determine choice of antibiotic. The opinion of the current author favours the recent Canadian guidelines [47], which advocate the use of particular antibiotics that have been shown to achieve superior bacteriological eradication for patients with risk factors for poor outcomes (severe chronic obstructive pulmonary disease box in algorithm). These patients will also be more at risk for being infected with an antibiotic resistant strain because of the frequency with which they are treated with antibiotics.

\section{REFERENCES}

1 Wilson R. Bacteria, antibiotics and COPD. Eur Respir J 2001; 17: 995-1007.

2 Prescott E, Lange P, Vestbo J. Chronic mucus hypersecretion in COPD and death from pulmonary infection. Eur Respir J 1995; 8: 1333-1338.

3 Wilson R, Dowling RB, Jackson AD. The biology of bacterial colonization and invasion of the respiratory mucosa. Eur Respir J 1996; 9: 1523-1530.

4 Fletcher C, Peto R, Tinker C, Speizer FE. The natural history of chronic bronchitis and emphysema. New York, Toronto, Oxford University Press, 1976.
5 Anthonison NR. The British hypothesis revisited. Eur Respir J 2004; 23: 657-658.

6 Murphy TF, Sethi S. Bacteria infection in chronic obstruction pulmonary disease. Am Rev Respir Dis 1992; 146: 1067-1083.

7 Vestbo J, Prescott E, Lange P, the Copenhagen City Heart Study Group. Association of chronic mucus hypersecretion with FEV1 decline and chronic obstructive pulmonary disease morbidity. Am J Respir Crit Care Med 1996; 153: 1530-1535.

8 Kanner RE, Anthonisen NR, Connett JE for the Lung Health Study Research Group. Lower respiratory illnesses promote FEV1 decline in current smokers but not exsmokers with mild chronic obstructive pulmonary disease. Am J Respir Crit Care Med 2001; 164: 358-364.

9 Donaldson GC, Seemungal TAR, Bhomik A, Wedzicha JA. Relationship between exacerbation frequency and lung function decline in chronic obstructive pulmonary disease. Thorax 2002; 57: 847-852.

10 Spencer S, Calverley PMA, Burge PS, et al. Health status deterioration in patients with COPD. Am J Respir Crit Care Med 2001; 163: 122-128.

11 Spencer S, Jones PW. Time course of recovery of health status following an infective exacerbation of chronic bronchitis. Thorax 2003; 58: 589-593.

12 Wilkinson TMA, Patel IS, Wilks M, Donaldson GC, Wedzicha JA. Airway bacterial load and FEV1 decline in patients with chronic obstructive lung disease. Am J Respir Crit Care Med 2003; 167: 1090-1095.

13 Patel IS, Seemungal TA, Wilks M, et al. Relationship between bacterial colonisation and the frequency, character and severity of COPD exacerbations. Thorax 2002; 57: 759-764. 
14 Gump DW, Phillips CA, Forsyth BR, McIntosh K, Lamborn KR, Stouch WH. Role of infection in chronic bronchitis. Am Rev Respir Dis 1976; 113: 465-474.

15 Sethi S, Evans N, Grant B, Murphy TF. New strains of bacteria and exacerbations of chronic obstructive pulmonary disease. N Engl J Med 2002; 347: 465-471.

16 Obaji A, Sethi S. Acute exacerbations of chronic bronchitis: what role for the new fluoroquinolones? Drugs Aging 2001; 18: 1-11.

17 Stockley RA, O'Brien C, Pye A, et al. Relationship of sputum colour to nature and outpatient management of acute exacerbations of COPD. Chest 2001; 117: 1638-1645.

18 Monso E, Ruiz J, Rosell A, et al. Bacterial infection in chronic obstructive airways disease: a study of stable and exacerbated patients using the protected specimen brush. Am J Respir Crit Care Med 1995; 152: 1316-1320.

19 Monso E, Rosell AI, Boret G, et al. Risk factors of lower airway bacterial colonization in chronic bronchitis. Eur Respir J 1999; 13: 338-342.

20 Zalacain R, Sobradillo V, Amilibia J, et al. Predispoing factors to bacterial colonisation in chronic obstructive pulmonary disease. Eur Respir J 1999; 13: 343-348.

21 Peta R, Marchesani F, Agostinelli C, et al. Airway microbial flora in COPD patients in stable clinical conditions and during exacerbations: a bronchoscopic investigation. Monaldi Arch Chest Dis 1998; 53: 262-267.

22 Bresser P, van Alphen L, Habets FJM. Persiting Haemophilus influenzae strains induce lower levels of interleukin-6 and interleukin-8 in H292 lung epithelial cells than non-persisting strains. Eur Respir J 1997; 10: 2319-2326.

23 Soler N, Ewig S, Torres A, Filella A, Gonzalez J, Zaubet A. Airway inflammation and bronchial microbial patterns in patients with stable chronic obstructive pulmonary disease. Eur Respir J 1999; 14: 1015-1022.

24 Banerjee D, Khair OA, Honeybourne D. Impact of sputum bacteria on airway inflammation and health status in clinical stable COPD. Eur Respir J 2004; 23: 685-691.

25 Bandi V, Jakubowycz M, Kinyon C, et al. Infectious exacerbations of chronic obstructive pulmonary disease associated with respiratory viruses and non-typeable Haemophilus influenzae. FEMS Immunol Med Microbiol 2003; 37: 69-75.

26 Qiu Y, Zhu J, Bandi V, et al. Biopsy neutrophilia, neutrophil chemokine and receptor gene expression in severe exacerbations of chronic obstructive pulmonary disease. Am J Respir Crit Care Med 2003; 168: 968-975.

27 Gump DW, Phillips CA, Forsyth BR, et al. Role of infection in chronic bronchitis. Am Rev Respir Dis 1976; 113: 465-473.

28 Calder MA, Schonell ME. Pneumococcal typing and the problem of endogenous or exogenous re-infection in chronch bronchitis. Lancet 1971; 1: 1156-1159.

29 McHardy VU, Inglis JM, Calder MA, et al. A study of infective and other factors in exacerbations of chronic bronchitis. Br J Dis Chest 1980; 74: 228-307.

30 Groeneveld K, van Alphen LV, Eijk PP, et al. Endogenous and exogenous re-infection of Haemophilus influenzae in patients with chronic obstructive pulmonary disease: the effect of antibiotic treatment on persistence. J Infect Dis 1990; 161: 512-517.
31 Fisher M, Akhtar AJ, Calder MA, et al. Pilot study of factors associated with exacerbations in chronic bronchitis. BMJ 1969; 4: 187-192.

32 Baigelman W, Chodosh S, Pizzuto D, et al. Quantitative sputum gram stains in chronic bronchial disease. Lung 1979; 156: 265-270.

33 Murphy T, Sethi S, Niederman M. The role of bacteria in exacerbations of COPD (a constructive view). Chest 2000; 118: 204-209.

34 Sethi S, Wrona C, Grant BJB, Murphy TF. Strain-specific immune response to Haemophilus influenzae in chronic obstructive pulmonary disease. Am J Respir Crit Care Med 2004; 169: 448-453.

35 Sethi S, Brauer A, Lobbins P, Eschberger K, Murphy TF. Systemic and mucosal immune responses to Moraxella catarrhalis in chronic obstructive pulmonary disease. Am J Respir Crit Care Med 2004; 169: A208.

36 Sethi S, Wrona C, Murphy TF. Serum immune response to colonization by Haemophilus influenzae in chronic obstructive pulmonary disease. Am J Respir Crit Care Med 2004; 169: A864.

37 White AJ, Gompertz S, Bayley DL, et al. Resolution of bronchial inflammation is related to bacterial eradication following treatment of exacerbations of chronic bronchitis. Thorax 2003; 58: 680-685.

38 Hill AT, Campbell EJ, Hill SL, Bayley DL, Stockley RA. Association between airway bacterial load and markers of airway inflammation in patients with stable chronic bronchitis. Am J Respir Crit Care Med 2000; 109: 288-295.

39 Dowling RB, Rayner CFJ, Rutman A, et al. Effect of salmeterol on Pseudomonas aeruginosa infection of respiratory mucosa. Am J Respir Crit Care Med 1997; 155: 327-336.

40 Saint SK, Bent S, Vittinghoff E, et al. Antibiotics in chronic obstructive pulmonary disease exacerbations: a metaanalysis. J Am Med Assoc 1995; 273: 957-960.

41 Anthonisen NR, Manfreda J, Warren CPW, et al. Antibiotic therapy in exacerbations of chronic obstructive pulmonary disease. Ann Intern Med 1987; 106: 196-204.

42 Allegra F, Blasi B, de Bernardi R, Cosentini P. Antibiotic treatment and baseline severity of disease in acute exacerbations of chronic bronchitis: a re-evaluation of previously published data of a placebo-controlled randomised study. Pulm Pharmacol Ther 2001; 14: 149-155.

43 Wilson R, Kubin R, Ballin I, et al. Five day moxifloxacin therapy compared with seven day clarithromycin therapy for the treatment of acute exacerbations of chronic bronchitis. J Antimicrob Chemother 1999; 44: 501-513.

44 Wilson R, Schentag JJ, Ball P, Mandell LA. Comparison of gemifloxacin and clarithromycin in acute exacerbations of chronic bronchitis and long-term clinical outcomes. Clin Therap 2002; 24: 639-652.

45 Wilson R, Allegra L, Huchon G, et al. Short-term and longterm outcomes of moxifloxacin compared to standard antibiotic treatment in acute exacerbations of chronic bronchitis. Chest 2004; 125: 953-964.

46 Wilson R. Outcome predictors in bronchitis. Chest 1995; 108: 53s-57s.

47 Balter MS, LaForge J, Low DE, Mandell L, Grossman RE. Canadian guidelines for the management of acute exacerbations of chronic bronchitis. Can Respir J 2003; 10: Suppl B, 3B-32B. 